\title{
Five
}

\section{FROM MEANING TO MORALITY IN KOVESI AND HARRISON}

\section{Alan Tapper \\ 1. Introduction}

It is stating the obvious to say that Ludwig Wittgenstein looms large in Bernard Harrison's philosophical world. A little less obvious is the influence of Peter Geach's attack on an abstractionist account of concept-formation in his Mental Acts (1957). Two Australian philosophers also play a part in Harrison's thinking. One, Len Goddard, contributes a discussion of the practice of counting (1961) that, in Harrison's hands, is extended to become an account of the practical role of concepts in thought and action. The other, Julius Kovesi, is the subject of this essay. I will elucidate the connection between Harrison and Kovesi, a connection that for various reasons might easily be missed.

Today, even readers who know Harrison's writings well may not know much about Kovesi. His name and work have slipped off the radar. A Hungarian who escaped across the Soviet-controlled border and migrated to Australia at age eighteen, he studied at Oxford in 1956-1958 under J. L. Austin. Most of his academic career was spent at the University of Western Australia in Perth. His only book, Moral Notions, was published in 1967 (reprint, 2004b). He died in 1989, at age fifty-nine. His interests were as much in the history of ideas as in philosophy. A collection of his essays was published posthumously under the title Values and Evaluations: Essays on Ethics and Ideology (1989).

Moral Notions is as much a study in the nature of concepts as a book on moral philosophy. In a short space, it argues from an account of concepts to an account of the role of concepts in moral thought and reasoning, and then to a discussion of the relations between facts, descriptions, evaluations, and moral judgment. In 1969, Bernard Mayo wrote an enthusiastic Critical Notice of Moral Notions in Mind, and Harrison had been a student of Mayo's. But from initial high fame, Kovesi's book soon sank to relative obscurity. At that time, English-language philosophy turned rapidly away from conceptual analysis and toward metaphysics and epistemology. Harrison has written of:

the relatively sudden turn in philosophy, in the late $60 \mathrm{~s}$ and early $70 \mathrm{~s}$, away from the generally anti-metaphysical outlook promoted by Wittgenstein and Austin to the renewed interest in metaphysics - in 
very various forms, including [W. V. O.] Quine's semantic holism, [Peter] Strawson's neo-Kantianism, [John] McDowell's neo-Hegelianism, [Michael] Dummett's anti-realism, [Hilary] Putnam and [Saul] Kripke's essentialism, and so on and so forth-which has dominated the scene more or less ever since. (Personal communication, 6 November 2009)

Not all philosophers forgot Kovesi when this turn was taken, and Harrison was one for whom Kovesi remained a source of ideas and inspiration. Their connection became a personal one. In 1978, Harrison spent a year at the University of Western Australia, where he could talk philosophy with Kovesi on a regular basis. He describes Kovesi as "a delightful, sublimely intelligent man" and says he regards Moral Notions as "a major contribution to moral philosophy" (personal communication, 24 September 2008). In a 1978 essay he remarks, "The only book on ethics written since the war which is wholly free from the influence of positivism is, so far as I am aware, Julius Kovesi's Moral Notions" (pp. 260-261).

I will show that Harrison and Kovesi are complementary thinkers, interested in similar questions, and arriving at closely comparable answers. Kovesi's philosophical world consisted, in the near view, of Austin, Wittgenstein, R. M. Hare, and, in the longer view, of David Hume, John Locke, Aristotle, Plato, and Socrates. (Karl Marx and Marxism were also important, though in a different way, and Kovesi's interests were broad ones.) Harrison's work is inspired by the conceptual themes of Wittgenstein, Geach, Goddard, and Kovesi, but his thought developed in a context dominated by the revival of metaphysical questions after 1970. In this essay, I will summarize the theory of concepts and meaning that they shared and the way they have used this theory to make sense of morality.

\section{The Theory of Concepts}

For much of his career, Harrison has been steadily constructing a theory of concepts, one grounded in a naturalistic account of human abilities. Philosophers of a Wittgensteinian bent have sometimes adopted an anti-theoretical and anti-empirical stance, while defending the importance of conceptual analysis as the primary method of doing philosophy. Though thoroughly Wittgensteinian, Harrison, by contrast, has sought an account of concepts that is theoretically coherent, empirically sound, and philosophically productive. It is a large enterprise.

I suggest Harrison's theory of concepts can be summarized - too crudely, no doubt - in four main points, based on the complex argument in Word and World, the monumental work he wrote with Patricia Hanna (Hanna and Harrison, 2004). First, concepts are to be explained in terms of practices. The practices of counting and measuring are his standard examples; carpentry is another example he uses. The example of counting is derived from Goddard, 
though the basic idea of concepts being grounded in practices comes from Wittgenstein (ibid., pp. 179-190). Second, concepts come in families or fields. Concepts do not stand alone, but are interconnected. Interconnected concepts form a "logical space." Third, he denies that concepts are formed by abstraction from experience-this was Geach's main point in Mental Acts: "the mind makes concepts, and this concept-formation and subsequent use of the concepts formed is never a mere recognition or finding" (1957, p. 40).

But Harrison shows how concepts are nevertheless related to experience. The relationship involves two steps, not one. Philosophers have commonly tried to reduce the relationship to a single word-to-world relation, typically some variation on the idea of "referring," which is usually construed as a kind of one-to-one "naming." $\mathrm{He}$ argues that it is a two-stage relation, involving both relevance and application.

Concepts play the role of allowing us to pick out facts in the world that are relevant to a certain description. One who understands the concept of $\mathrm{X}$ (length, for example) thereby knows what sorts of facts are relevant to determining the Xness (length) of a certain object. Thus, he can operate with the concept, in pursuit of the practice (measuring, for example) that defines the concept (see especially Hanna and Harrison 2004, pp. 48-51).

Fourth, the world itself has no conceptual character:

There is nothing in the world to which a concept corresponds: concepts are creatures of the fertility of the mind in devising practices. As linguistic creatures we confront a world that offers itself, mutely and preconceptually, as the foundation on which we erect our practices. (Ibid., p. 352)

The world has, as he puts it, no "assertoric content"; it does not impose its character on us, compelling us to form the concepts we do form, because it has no such (linguistic) character. Rather, we form concepts as part of our practical involvement with the world. Philosophers have mistakenly sought to ground metaphysical realism in the "content" of the world, whereas realism can and should be grounded in our practical engagement with the world.

Harrison has shown how his second and third features of concepts are logically connected. When we understand a concept, we not only know what facts are relevant to affirming the truth of that concept as a descriptor, but we also know that other facts are inconsistent with that description. We also know that other descriptions are entailed by denials of the first description. Some predicates are quite unrelated to each other; others are related, and understanding those predicates involves understanding them as related. Interrelated concepts "form a set whose members are intrinsically alternative to one another, and they do so precisely in the sense that what is asserted in denying any one of them of an object is the applicability to that object of one or other 
of the remaining ones" (ibid., pp. 211-212). If I deny that it is sunny, I imply that it is cloudy or that it is nighttime or some other of a limited set of alternative cognate descriptions. But in denying that it is sunny, I do not imply that it is Thursday, or that the price of platinum is about to plummet, or any other of an unlimited set of unrelated alternatives.

Harrison's first and fourth points together allow him to construct a distinctive metaphysical standpoint. Those Wittgensteinians and pragmatists who emphasize the practice-based function of concepts have tended to see themselves as, metaphysically speaking, committed to anti-realism, or (as it was once dubbed) "Wittgensteinian fideism." Those who emphasize the empirical derivation of concepts at the expense of the social construction aspect have tended to argue for metaphysical realism. Harrison seeks to avoid both of these competing orthodoxies in favor of what he has come to call "relative realism." This doctrine holds:

concepts are relative to practices; that what concepts a natural language honours is determined not by the nature of things, but by the specific range of practices that enter into the constitution of that particular natural language. (Ibid., p. 58)

But, although "relative" in this sense, concepts are not detached from reality, since practices engage with reality.

Contact between thought and the world is established, not at the level of the conceptual or the assertoric, but lower down, at the level of the practices, through which the concepts of the conceptual and the assertoric become accessible to us. At that level we confront phenomena directly, through the medium of practice, not through that of propositional thought. (Ibid., p. 367)

Language is therefore not a "prison house."

Kovesi's account of concepts, as set out in the first two chapters of Moral Notions, can be summarized in six points. First, concepts are rational, in that they serve our needs and interests. Concepts can be understood as rulegoverned, but they are better understood as reason-governed. Wittgensteinian talk of rule-following should be reconstructed as a point about reason-giving. Second, concepts are public and social, in that they are formed from the point of view of anyone.

In establishing a concept $\mathrm{X}$, we must also establish ways of recognizing the presence of $\mathrm{X}$, which Kovesi terms "recognitors," and:

the process of establishing the recognitors and their significance must be public. This must be so not only because other people have to be able to 
use our terms but because not even one single person, not even the inventor of the notion, could use the new word in a consistent way without sharing its use with others. Furthermore, the possibility of anyone being able to use a term in the same way is the guarantee for the fact that the recognitors and their significance have been properly selected and established. (1967, p. 55; 2004b, pp. 41-42)

For a discussion of Kovesi's idea of recognitors and its relevance to how we think of personhood, see the Afterword in the reprint of Moral Notions (Ewin and Tapper, 2004, pp. 147-155).

Third, concepts are multifunctional, in that they serve diverse needs and interests, including our moral, prudential, scientific, and technological needs and interests (Kovesi, 1967, p. 146; 2004b, p. 105). Fourth, concepts are polymorphic, in that any given concept might subsume other concepts and also be subsumed under another concept. This terminology-polymorphism and subsumption - is not Kovesi's but it corresponds to his thinking. He talks of "higher order notions" as having a variety of "lower order notions" as "instances" (1967, p. 156; 2004b, p. 112).

Fifth, concepts are "open-textured." New ways of instantiating any given concept are always possible:

We cannot give a complete enumeration of the conditions that must be fulfilled for the proper use of a term. Not because of the indefinite number of these conditions, but because these conditions have an open texture. Nor can it be stated how many of these conditions must be present and how many may be absent. (1967, pp. 7-8; 2004b, p. 9)

Finally, concepts are "free-standing" (my term), in that they are not governed by the way they are instantiated in the world. Rather, how a concept is instantiated is governed by its point or purpose, which in turn arises from the needs and interests it serves (1967, pp. 15-23; 2004b, pp. 15-20).

Kovesi takes as given the idea that concepts are practical-Harrison's first (Wittgensteinian) point. "Language games are not word games; they are activities of which language is a part," he says $(1967$, p. 42; 2004b, p. 33). Like Harrison, he accepts Geach's thesis that concepts are not the product of abstraction or induction from sets of similar-seeming observable features. Like Harrison also, he does not think that the world is conceptually structured. There is a real world of "raw data," but we can say nothing about that world:

Whatever might be the advantages of constructing a language that would mirror the world of data, our language functions differently from such a language. In our language, to be able to understand the significance or the meaning of a term, we have to be able to follow a rule in 
using that term, not to be able to perceive an entity of which our term is a name. $(1967$, p. $20 ; 2004$ b, p. 18$)$

I have given this summary without using the key terms that Kovesi tried to introduce into the philosophy of language: "formal element" and "material element." The formal element of a concept is its point or purpose or the reason for its formation. The material elements of a concept are the ways in which instances or kinds of the concepts may vary while remaining instances or kinds of that concept. They are the variables of the concept. The material elements never determine the nature of the concept:

The reasons why we cannot define what a thing or act is in terms of their material elements, or why we cannot make valid deductive arguments where the premisses contain only material elements and the conclusion tells what the thing or act is . . . has to do with the fact that the sort of things that can constitute a thing or act, their material elements, cannot be enumerated in a final list. $(1967$, p. $8 ; 2004 b$, p. 10)

The formal element of a concept determines the material elements. A certain set of elements in a particular case will count as an instance of the concept only if the elements amount to that concept and it is the presence or absence of the formal element - that is, the point or purpose of the concept - that decides this.

Kovesi's terminology did not catch on, even amongst some of those who saw the point he was making and regarded it as important and sound. Roger A. Shiner and Jerome E. Bickenbach (1976) and R. E. Ewin (1981; 2002, pp. 2747) found no difficulty with the terminology, and Ewin (2002) and Brian Morrison (2002) are helpful on the relation between reason, naturalistically understood, and concept-formation. But J. M. Brennan (1977) developed a Kovesian argument without the terminology, as did Peter A. French (1979).

One likely reason for the terminology's failure is that it had metaphysical overtones. Yet Kovesi twice denied that he was making any metaphysical claims: "By introducing these terms I am not going to introduce any metaphysical entities" (1967, p. 3; 2004b, p. 7), and "I am not arguing over the inventory of the universe" (1967, p. 19; 2004b, p. 17). His argument was about semantics, not metaphysics.

Others may have seen Kovesi as having Platonic tendencies and been put off by that. But his enthusiasm for Plato was non-metaphysical. He read Plato as doing the sort of semantics he himself was trying to formulate. Plato's Forms are Kovesi's formal elements. Plato contrasts the Forms with the "dispersed plurality" of the world before we bring it under some Form, and this is what Kovesi means by his "material elements" (1967, pp. 136-139; 2004b, pp. 98-99). Note also, Kovesi's non-metaphysical version of Plato is 
developed in "Did Plato Turn Himself Upside Down?" (2004a, pp. 119-126). He was not trying to eliminate or in any way downgrade the material world:

Since what a thing or act is is not something extra over and above what its material elements amount to, if we want to change anything, or any act, then we have to change the material elements. If we want to turn a particular ugly object into a beautiful object we have to do something to it, and the nature of the universe is such that doing something to a thing always has a quantitative aspect in some sense. $(1967$, p. $68 ; 2004$ b, p. 51)

His point is, rather, that to give any description of the material world is to engage in a rational conceptual activity. To describe correctly involves having reasons, and these reasons are embodied in our concepts, which are themselves a function of our human needs and interests.

Kovesi was not attempting to construct a metaphysics; he touches only briefly on the relation between semantics and metaphysics. Harrison, however, has had to face the full challenge of analytical philosophy's turn away from conceptual analysis and toward metaphysics in the work of Quine, Strawson, McDowell, Dummett, Putnam, and Kripke, amongst many others. His theory of concepts takes on this challenge (1991a). A key step in his analysis is to identify the metaphysical positions to which he is opposed - the philosophies that subscribe to what Hanna and Harrison call "referential realism"- as themselves at least partly based on a theory of concepts:

[Referential realism] enshrines, in many of its forms, the doctrine that unless a proper name or general term corresponds to some entity whose existence owes nothing to language, no thought articulated in terms of it can have any bearing on any reality external to the mind. (2004, p. 53)

Word and World seeks to demonstrate that referential realism underpins much recent philosophy, to show its failings as a theory of concepts, and to offer relative realism as an alternative, which is traced back to (a certain reading of) Wittgenstein but also to Kovesi. The Kovesian element in this is, explicitly, the anti-reductionism implicit in Kovesi's account of concepts (ibid., pp. 53-56, 384; see also, on artifact concepts, pp. 286, 393), and I suspect there is an even broader "Kovesi factor" in the development of these ideas.

\section{Morality and Moral Concepts}

In this section, I will expound Kovesi's argument first and then discuss its connections with Harrison's work. The aim of Moral Notions was to explain the role of concepts in moral thought. It was not his aim, Kovesi says, to give an account of "the foundation of morality" or to explain "the moral point of 
view" (1967, p. 145; 2004b, pp. 104-105). His focus is on the logical features of moral concepts, the misconstrual of which has led moral philosophy down a number of blind alleys such as positivism, intuitionism, prescriptivism, sentimentalism, and existentialism. In that way, his work does imply something about how moral philosophy should be done.

Moral philosophy must start from the fact that we already possess a complex array of moral concepts. To do moral philosophy we must first examine the ways in which we classify the moral domain and distinguish between those concepts that are and those that are not moral concepts - though not too sharply, allowing for partial overlaps with politics, law, etiquette, religion, etc.

The concepts that define the field of morality have three key features. In Kovesi's view: "we find moral notions among those that we form about ourselves in so far as we are rule-following rational beings" (1967, pp. 147148). It follows that:

(a) moral notions have to be public twice over: they not only have to be formed from the point of view of anyone, but they also have to be about those features of our lives that can be the feature of anyone's life; (b) they provide not only the rules for our thinking about the world but also the rules for our behaviour, while other notions are not at the same time rules for the behaviour of their subject matter; (c) partly as a consequence of (b), if other notions did not exist those events that are their subject matter would still go on happening, but without moral notions there would be nothing left of their subject matter. (2004b, p. 106)

Moral concepts are constitutive of our social lives as well as descriptive of them; without such concepts we could have no social life. In the case of these concepts, the "direction of fit" runs both from word to world and from world to word because, in the moral domain, the "world" is the human social world.

The blind alleys of moral philosophy arise from two mistakes. First, moral philosophy has failed to recognize that moral concepts already take into account our wants and desires and decisions:

Our interests, wants and needs enter our social and moral notions twice. As in the case of scientific notions, they initiate and guide the selection of the recognitors - though these interests are not that of wanting to predict or manipulate but of wanting to promote or avoid certain thingsand second, the recognitors themselves are selected from our wants, needs, likes and dislikes. (1967, p. 54; 2004b, p. 41) 
We may differ in our wants and desires and decisions, but these differences take place within a shared conceptual environment, in which the moral concepts have been formed from the point of view of anyone.

Second, we make moral judgments in just the same way-logically speaking — as we make other judgments:

I am simply saying that knowing is different from perceiving, and we do not perceive something called murder; we know that certain acts are acts of murder in the same way as we know that certain objects are tables. (1967, p. 19; 2004b, p. 17)

This runs counter to the perennial desire of some philosophers to reduce knowing to perceiving. Kovesi allows that the two are barely distinguishable in the case of color judgments, but he contends that this case is the exceptional case, and in all other cases the gap between perceiving and knowing is readily observed (on color terms, cf. Harrison, 1973). That gap is explained in terms of Kovesi's distinction between material and formal elements. Perception may pick out a collection of material elements, but only knowledge of the meaning of a concept enables us to bring that collection under some description.

This is not idealism or anti-realism. The material facts are required as part of our judgments:

There must be some differences in the field of material elements between $x$ and $y$ if we want to judge them differently, but we would not know what differences would entitle us to do so without the formal element. . . . it is pointless to ask how we move from the material elements to what we say the thing or action is once we realize that we select the material elements because they constitute that thing or act. $(1967$, p. 31 ; 2004b, p. 26)

Judgments of sameness are governed by the formal element, not by the material elements. Two things or actions or events are the same or similar only if their formal elements are the same or similar. This point applies to all concepts, to moral concepts as much as to scientific or prudential or technological concepts. It is simply a basic feature of the logic of concepts.

Kovesi's general point might be summed up as: there is nothing logically special about moral concepts; they are special only in that they operate in the moral domain. The moral concepts of goodness and rightness must follow the same logic as applies to any other concepts:

we cannot say that two objects are exactly the same in every respect except that one is good while the other is not: that they differ only in their goodness. . . . Similarly, ... two acts cannot be the same in every re- 
spect except in this, that one of them is right and the other is wrong; nor can we say that two situations are exactly the same except that in one I am under an obligation to do something, but not in the other. There must be some further difference between the two if one is right but the other is wrong, or if in one I am under an obligation but in the other I am not. (1967, p. 28; 2004b, p. 23)

Kovesi does introduce one novelty into his discussion of moral concepts. He distinguishes between "complete" and "incomplete" moral concepts. (To be fully consistent he would need to show how there might be complete and incomplete scientific, prudential, and technological concepts, but he does not go down that path.) His idea is that some concepts are formed completely from the moral point of view, while others are formed only partly from that point of view. Examples of complete moral concepts he lists are: murder, prejudice, cruelty, stealing. In those cases, the wrongness of what they describe is built into the description. Someone who did not understand that murder is wrong would not understand the concept of murder.

If someone understands the notion of murder or stealing, to say that they are wrong does not give him any more information. ... we have a special word that we use to remind ourselves of the point of forming notions like murder, prejudice, cruelty, stealing: we use the word "wrong." (1967, p. 26; 2004b, p. 22)

As further examples we might add: rape, arson, bullying, negligence, blackmail, perjury, malfeasance, embezzlement, plagiarism, snobbery, hypocrisy, prudishness, and self-righteousness. A small number of complete moral concepts operate at a more general level: justice, injustice, kindness, unkindness, altruism, selfishness, etc. (Edmund L. Pincoffs put forward a useful taxonomy of moral concepts in Quandaries and Virtues [1986, pp. 73-100].)

Incomplete moral concepts are those that are not wrong or right by definition, but can be made right or wrong by "further specifications from the moral point of view" (Kovesi, 1967, p. 124; 2004b, p. 90). Kovesi gives the concept of lying as an example of an incomplete moral concept. Lying is morally wrong, except when a suitable justificatory explanation can be given, and such an explanation needs to be given whenever lying is suspected. A justification might be that the lying was required to save an innocent life. We could turn the concept of lying into a complete moral concept if we invented the idea of "saving deceit" to carve out the case of justifiable lying, thereby leaving the modified concept of lying to cover those cases when it is always wrong, just as murder is always wrong (1967, pp. 104-110; 2004b, pp. 76-79).

Kovesi also discusses love as an incomplete moral concept (1967, pp. 137-138; 2004b, pp. 98-99, 122, 132). Other possible examples might be: 
homicide, abortion, assassination, civil disobedience, torture, and capital punishment. For a discussion of lying in Kovesi, see "MacIntyre and Kovesi on the Nature of Moral Concept" (Ewin and Tapper, 2012, pp. 123-138). The example of lying illustrates the point that, for Kovesi, moral concepts-like any other kinds of concepts - are open to rational revision. "Lying" can be revised by the invention of "saving deceit." That is an example of the revision of an incomplete concept by means of applying complete concepts to it. "Revenge" may be revised by the instituting of policing and legal practices that replace the point of revenge (Kovesi, 1970, pp. 63-64; 1998, p. 23).

Complete moral concepts - concepts formed wholly from the moral point of view - constitute the core of morality and the basis of moral judgments. Faced with a complex situation, we bring its messy features under the array of concepts at our disposal. The applicability of a complete moral concept such as murder will settle the morality of the case. If no complete moral concept is straightforwardly applicable, we reason analogically: Are there features of the situation that resemble the features of some complete moral concept? The features we look for are features relevant to our moral concepts. In other kinds of situation we would want to pick out features relevant to our scientific interests or our prudential or technological interests.

Each of these categories describes a domain within which are numerous and innumerable "facts" specific to that domain. The facts can be represented as descriptions, but description enters into all of our categories, including the moral domain. But we never reason from facts in one domain to values in another. We do reason from facts in one domain to values in the same domain:

Our different sorts of notions do not cross the floor of the house: in order to get to the other side they have to go back to their constituencies and be elected for the other side. If certain material elements have been elected to serve a purpose then they serve that purpose. In order for them to serve another purpose they have to go through the same process again that enables them to serve a particular purpose, they have to be elected again. (Kovesi, 1967, pp. 64-65; 2004b, pp. 48-49)

In discussing Harrison's moral thought, I will draw on two discussions: his "Moral Judgment, Action, and Emotion" (1984, pp. 295-321), which deals with themes closely connected with the moral theory of Moral Notions, and the Epilogue of Word and World, which sets morality in the context of the philosophy of language (Hanna and Harrison, 2004, 347-382; see also Harrison, 1975, especially chap. 4; 1978; 1991a; and 2012, where he deals directly with Kovesi as a moral philosopher). For both Kovesi and Harrison, David Hume is the philosopher who most requires an answer.

In "Moral Judgment, Action, and Emotion," Harrison seeks to answer Hume's account of moral motivation. Hume divides morality into two parts: 
benevolence and justice. He seeks to ground benevolence in our capacity for sympathy, and justice in our rational self-interest. Sympathy arises naturally whenever we observe distress in others. Just social institutions serve the interests of each of us, and we value them for the advantages they afford each of us individually. Thus, sympathy and rational self-interest together give morality its grounding. Without such grounding, Hume thinks, we would be at a loss to explain how morality is even possible.

The problem of finding a satisfactory account of moral motivation is a key topic in recent moral philosophy, and Hume's account of the problem is now widely regarded as classical. Harrison and Kovesi are united in finding Hume's account misconceived, while accepting the need for some naturalistic explanation of our moral capacities. Harrison's reply to Hume involves an analysis of the concepts of friendship and trust. He is arguing for this general claim:

Moral emotion and moral commitment on the one hand, moral rules and moral concepts on the other, are simply different aspects, inextricably because conceptually connected, of moral relationship. (1984, p. 313)

A long quotation is required here:

Morality is social, but not on that account societal. It is what connects individual to individual, not what connects individuals taken one by one to a notional individual representing the abstract collectivity of the common life which is founded upon and made possible by moral relationship: the distinction is one which social theorists and social engineers neglect at their, and our, peril. Nor, on the other hand is the interest we take in morality a matter of each bosom resonating in harmony with the winds of feeling which agitate its fellows. If that were the case it would be hard to see why morality should generate a conceptual scheme at all, or lend itself to the irritatingly fine distinctions, between heroism and heroics, friendship and flattery, sympathy and a sense of desert [distinctions discussed earlier in the essay], which obstruct the free passage of the more grandiose and schematic kinds of theorizing about morality. Morality is rooted more deeply in us than either social conditioning or nervous sensibility could root it, because its imperatives spring from the formal conditions for the existence of types of relationship into which human beings must enter with one another, because such relationships provide an essential framework around which the personalities and goals of individuals organize themselves. (Ibid., pp. 313-314)

The stress here on the importance of actual moral concepts and distinctionsas opposed to schematic theorizing, on the one hand, and pre-conceptual raw 
emotion, on the other-is Kovesian (regardless whether it is derived from Kovesi). Harrison is not simply explicating these concepts; he is also describing how trust and friendship actually work in everyday life. He is showing how, in Kovesi's terms, the concepts of trust and friendship "provide not only the rules for our thinking about the world but also the rules for our behavior" (1967, p. 148; 2004b, p. 106).

Harrison is going a long step beyond just analyzing the "logical features of moral concepts." He is presenting a substantive moral position. Morality is both "social" and "individual" in the special senses he intends. "Friendship" and "trust" are intrinsic elements of morality. (These themes of trust, friendship, moral relationship, personhood, and social identity are developed more fully in Harrison, 1989.)

Our motivation to be moral:

[to] sometimes own up, [to] refrain from stealing a march on friends, and so on, even when [we] could by doing otherwise reap advantages far outweighing, in the scales of ordinary prudential rationality, any consequent disadvantage (Harrison, 1984, p. 295)

arises from our aptitude for these sorts of social relationships. It is only a partial and incomplete aptitude, of course. But it is sufficient to provide an answer to Hume's problem of motivation. This is how we are, much of the time. Harrison's argument requires that we recognize this picture as well as accept his conceptual analysis. "Moral Judgment, Action, and Emotion" (Harrison, 1984) includes a footnote credit to Kovesi. Harrison puts forward an account of trust that, as he puts it, "brings out the way in which the concept of trust, like other moral con- cepts, is rooted in certain specific kinds of convention. (ibid., p. 309)

It is perhaps not at first sight a Kovesian point, but further reflection shows what he has in mind. Kovesi contended that all concepts, whether "murder" or "table" or "pain" (or whatever), require agreement not only on the point of the concept in our lives - the "formal element"- - but also on the sorts of facts that we take as indicators - or "recognitors," to use his termof the presence of the act or thing or sensation (or whatever) to which the terms refers.

What counts as an $\mathrm{X}$ is a public matter, signified by certain conventions by means of which we can recognize the presence of $X$. In the case of trust, Harrison contends, A trusts B only if " $\mathrm{A}$ is willing to rely on B's unwillingness to allow a justified convention-backed claim of A's to be neglected or overridden" (ibid., p. 309). In the case of friendship, trust of this sort must be the normal condition of A's relation to B and of B's relation to 
A. Friends are not friends if they do not care spontaneously for each others' rights and interests.

Kovesi also discusses the way in which the concept of friendship enters into its practice:

We can work out ... as a theoretical exercise, what is implied in the notion of a friend. In analysing the concept we work out what is entailed in being a friend, what behaviour we expect from friends, with what intentions they do what they do, and so on. And when I am a friend, I have to act out in my life the implications of the concept. When someone reproaches me by saying 'I do not mind you doing that but do not call yourself a friend' he is pointing to the logical incompatibility of my action and my describing myself as a friend. Of course if I have reason to take on a different description I can cease to regard myself as a friend. But my description of myself needs justification just as much as the description of anything else. Moreover, changing it is itself an action, just as much as resigning, marrying or divorcing or joining the resistance movement are actions. (1979, p. 110; 1998, pp. 51-52)

The practice of friendship revolves around the concept of friendship, which itself is collectively created and publicly understood.

We now jump forward twenty years to Hanna and Harrison's Word and World, specifically to the last section- "The Human and the Subjective"-of that book's longish "Epilogue."

Books on the metaphysics of realism and anti-realism do not usually end with talk about novels, literary criticism, theology, and ethics, and it is not obvious that the argument of Word and World required a discussion of the objectivity of the humanities. The connection here is that, unlike the natural sciences, these do not seem like objective disciplines. Students of human culture, it seems, do not "arrive at a common moral vocabulary in terms of which to pursue their enquiries" and therefore seem to be "occupied with nothing real, but rather with figments of discourse, fancies of the mind" (Hanna and Harrison, 2004, p. 368). Ethics, especially, seems vulnerable to this sort of attack, the influence of which "lurks everywhere in our intellectual and cultural life" (Hanna and Harrison, 2004, pp. 368-369; the connection between philosophy of language, especially the theory of concepts, and literary theory is discussed in Harrison's "Wittgenstein and Scepticism," 1991b).

Nevertheless, the theory of concepts developed in the book as a whole does suggest that "objectivity and the culturally artifactual are not the polar opposites they are commonly supposed to be, but rather part and parcel of one another" (Hanna and Harrison, 2004, p. 376). They are not sharply opposed, because moral concepts are not sharply opposed to their referents. 
Harrison and Hanna take the concept of justice as their example:

Justice is, as we say, "a reality" in a society in which it is a reality, because in those societies the institutions for establishment and application of justice are (to a great extent) scrupulously maintained and conducted, and are respected by the vast majority of the citizens. Justice exists in such a society, no doubt, only because it is, in this sort of way, continuously willed into existence by the citizens, acting both individually and collectively. If they ceased to will in that way it would cease to exist. But as long as it is, in this way, borne up on a continuously flowing tide of settled wills, it exists, as a perfectly real, perfectly "objective" feature of the society it characterises. (Ibid.)

We might doubt whether any social life is possible without a concept of justice (on the grounds that, as Augustine of Hippo suggested, "states without justice are but robber bands enlarged" [1972, p. 139], and that all that would remain is a war of each against each), but that is a point for another discussion.

Social life can function adequately without many of the concepts that populate the discourse of the humanities. On the other hand, as Hanna and Harrison argue, moral and aesthetic concepts are not "conceptual phantoms" or "arbitrary counters," but the product of our rational cultural practices. These practices are not simply "descriptive" but rather "constitutive" of our lives.

Kovesi, I think, went a little further than this. He contended that our moral and social concepts, far from being less objective than our scientific concepts, are even more rational than them. Moral and social concepts are both guides to our actions and guides for our response to the actions of others. When we form such concepts we form them with regard to the needs and interests of anyone, ourselves included, so all relevant parties get to influence the structure of the concept. This, however, does not mean that such concepts are transparent to us. On the contrary:

in studying [our moral and social life] we have to chart out and explore intricate structures of conceptual relationships. But knowing this is not like knowledge of our intentions and in fact it is even more difficult to know than the physical world. The embodiments of our intentional endeavours in our language and culture are not the making of an individual agent, and yet only individuals can know, so however much that world is in a sense our creation, the maker and the knower are not the same. (Kovesi, 1979, p. 107; 1998, pp. 48-49)

Our moral and social concepts, though more objective, are, paradoxically perhaps, less readily knowable than our scientific concepts. 


\section{Conclusion}

This essay does not attempt much in the way of argument. My purpose has been documentary and descriptive, on the assumption that the commonalities and connections between Kovesi and Harrison are not well known and are worth tracing. If there is a sketchy conclusion it is fourfold. First, Harrison and Kovesi belong to a tradition of thought, now somewhat disparagingly referred to as "conceptual analysis," that goes back to Wittgenstein and Austin, and to which Goddard, Geach, and others contributed. Second, that tradition did develop a robust theory of concepts, and Kovesi and Harrison have been key contributors to the formation of that theory. Third, if Hanna and Harrison's account of referential realism is sound, then those many philosophers who turned away from conceptual analysis and toward (various kinds of) metaphysics may have done so on the basis of a theory of concepts that is far less robust than has been assumed. Fourth, if the theory of concepts shared by Harrison and Kovesi is sound, then we have available to us a philosophy of moral and cultural life that is not vulnerable to attacks based on assumptions about the exclusive objectivity of science. They have shown how we need not be held captive by that picture. But, as I say, here I have only gestured at these claims. 